RECUERO DIAZ: None declared, Fredeswinda Romero: None declared, Olga Sanchez Pernaute Grant/research support from: Merk Sharp Dome, Rubió, Paid instructor for: Glaxo Smith Kline, Actelion, Pfizer, Bristol Myers Squibb, Speakers bureau: Glaxo Smith Kline, Alexion, Novartis, Roche, Bristol Myers Squibb

DOI: 10.1136/annrheumdis-2019-eular.4265

\section{FRI0583 NEUROMYELITIS OPTICA OVERLAPS FREQUENTLY WITH SYSTEMIC RHEUMATIC DISEASES IN AFRICAN- AMERICANS: EXPERIENCE AT A LARGE US ACADEMIC MEDICAL CENTER}

Michael Belsky ${ }^{1,1}$, Hassan Amer ${ }^{2}$, Sunita Dia ${ }^{2}$, Christopher Collins ${ }^{1}$, Konstantinos Loupasakis ${ }^{1}$. 'MedStar Washington Hospital Center, Rheumatology, Washington, United States of America; ${ }^{2}$ MedStar Washington Hospital Center, Internal Medicine, Washington, United States of America

Background: Neuromyelitis optica (NMO) and neuromyelitis optica spectrum disorders (NMOSD) are immune-mediated demyelinating disorders of the central nervous system, primarily characterized by optic neuritis and longitudinal extensive transverse myelitis. Antibodies to aquaporin-4 (AQP4-lgG) are highly specific markers of NMOSD. The coexistence of NMOSD with systemic rheumatologic autoimmune disease has been well documented, especially systemic lupus erythematosus (SLE) and Sjogren syndrome (SS) [1]. Several recent studies have demonstrated that NMOSD may disproportionately affect black patients [2,3]

Objectives: Our objective was to characterize African-Americans diagnosed with NMO at our academic medical center, and identify any associated systemic rheumatologic autoimmune diseases.

Methods: We conducted a retrospective chart review of adult AfricanAmerican patients diagnosed with $\mathrm{NMO}$ at a single academic medical center between 2011 and 2017. The charts reviewed were identified using ICD codes for NMO, transverse myelitis and optic neuritis. The diagnosis of NMO was then confirmed as per the 2015 International Consensus Diagnostic Criteria. The diagnosis of SLE and SS were also confirmed based on existing diagnostic criteria.

Results: Of the 60 charts reviewed, 25 patients $(41.7 \%)$ met criteria for $\mathrm{NMO}$, and of those, 21 patients (84\%) were African-American. Of the 21 African-American NMO patients, 89.5\% $(n=19)$ were AQP4-IgG positive, $95.2 \%$ were women, and $38.1 \%$ had an associated systemic rheumatologic autoimmune disease (SLE 62.5\% and primary SS 37.5\%). In 60\% of the NMO patients with SLE, the diagnosis of NMO preceded the SLE diagnosis. Conversely, in $100 \%$ of the NMO patients with SS, the diagnosis of NMO either followed, or was made simultaneous to, the SS diagnosis. Notably, $80 \%$ of the SLE patients had primarily hematologic manifestations. ANA was positive in $78.6 \%$ of the African-American patients in whom ANA testing was performed $(n=14)$, with anti-SSA $(64.3 \%, n=14)$ and anti-SSB $(50 \%, n=11)$ the next most prevalent autoantibodies. Mean age of NMO onset was 46.7 years (SD 13.6). Transverse myelitis was the most common presenting manifestation (71.4\%), followed by optic neuritis $(61.9 \%)$.

Conclusion: Our population had a higher mean age of onset (46.7 vs 33 years) compared with other cohorts of seropositive NMO African-Americans [2]. Additionally, African-Americans with NMO at our institution had a higher female:male distribution than has been documented[3]. Not surprisingly, SLE was the most common associated systemic rheumatic disease in our cohort, however the frequency of SLE and ANA positivity in our NMO cohort was higher than has been reported $(23.8 \%$ and $78.6 \%$, respectively) [4]. Additional larger studies are needed to further explore how NMOSD in African-Americans may differ from other populations.

\section{REFERENCES:}

[1] Iyer A, Elsone L, Appleton R, Jacob A. A review of the current literature and a guide to the early diagnosis of autoimmune disorders associated with neuromyelitis optica, Autoimmunity, 47:3, 154-161

[2] Kim SH, Mealy MA, Levy $\mathrm{P}$, et al. Racial differences in neuromyelitis optica spectrum disorder. Neurology Nov 2018, 91 (22) e2089-e2099.

[3] Flanagan EP, Cabre P, Weinshenker BG, et al. Epidemiology of aquaporin-4 autoimmunity and neuromyelitis optica spectrum. Ann Neurol 2016;79:775-783.

[4] Pereira WLCJ, Reiche EMV, Kallaur AP, et al. Frequency of autoimmune disorders and autoantibodies in patients with neuromyelitis optica. Acta Neuropsychiatrica. 2017;29(3):170-178.

Disclosure of Interests: Michael Belsky: None declared, Hassan Amer: None declared, Sunita Dia: None declared, Christopher Collins Grant/ research support from: Exagen, Consultant for: Exagen, AbbVie, Speakers bureau: Exagen, AbbVie, Novartis, Konstantinos Loupasakis: None declared

DOI: 10.1136/annrheumdis-2019-eular.8185

\section{FRI0584 EFFICACY AND SAFETY OF RITUXIMAB FOR INDUCTION OF REMISSION AND MAINTENANCE OF IGG4-RELATED DISEASE: EXPERIENCE FROM AN ITALIAN NATIONAL REFERRAL CENTRE}

Corrado Campochiaro, Emanuel Della Torre, Marco Lanzillotta, Enrica Bozzolo, Elena Baldissera, Lorenzo Dagna. San Raffaele Scientific Institute, Unit of Immunology, Rheumatology, Allergy and Rare Diseases (UnIRAR), Milan, Italy

Background: IgG4-related disease(lgG4-RD) is a systemic fibro-inflammatory disease. Treatment is based on corticosteroids(CS) but up to $50 \%$ of patients may relapse. Rituximab(RTX) has emerged as an effective treatment option[1]

Objectives: To assess the free relapse rate(FRR) in patients receiving or not maintenance RTX therapy. Secondary outcomes: time to relapse, incidence of adverse events and differences in FRR between Group 2a and $2 \mathrm{~b}$ patients.

\begin{tabular}{|c|c|c|c|c|c|c|c|c|c|c|c|c|c|c|c|}
\hline $\begin{array}{l}\text { Patient } \\
\#\end{array}$ & $\begin{array}{c}\text { Age } \\
\text { (years) }\end{array}$ & Sex & $\begin{array}{c}\mathrm{N}^{\circ} \text { of } \\
\text { Organs } \\
\text { involved }\end{array}$ & $\begin{array}{l}\text { IgG4- } \\
\text { RD } \\
\text { RI }\end{array}$ & PGA & $\begin{array}{c}\text { ESR } \\
(\mathrm{mm} / \\
1 \mathrm{~h})\end{array}$ & $\begin{array}{l}\text { CRP } \\
\text { (mg/ } \\
\text { L) }\end{array}$ & $\begin{array}{l}\text { IgG4 } \\
(\mathrm{mg} / \mathrm{L})\end{array}$ & $\begin{array}{l}\text { Concomitant } \\
\text { DMARD } \\
\text { therapies }\end{array}$ & $\begin{array}{l}\text { Previous } \\
\text { DMARD } \\
\text { therapies }\end{array}$ & $\begin{array}{l}\text { Outcomes } \\
\text { after RTX } \\
\text { induction }\end{array}$ & Relapses & $\begin{array}{l}\mathrm{N}^{\circ} \text { of RTX } \\
\text { infusions }\end{array}$ & $\begin{array}{c}\text { RTX } \\
\text { Adverse }\end{array}$ & $\begin{array}{l}\text { Follow-up } \\
\text { (months) }\end{array}$ \\
\hline
\end{tabular}

\begin{tabular}{|c|c|c|c|c|c|c|c|c|c|c|c|c|c|c|c|}
\hline 1 & & & & & & & & & & & & & & & \\
\hline 1 & 29 & $\mathrm{~F}$ & $\begin{array}{c}3(\mathrm{Pm}, \mathrm{Ns} \\
\mathrm{Ph})\end{array}$ & 12 & 90 & 38 & 25 & 1001 & No & CTX & PR & No & 1 & No & 32 \\
\hline 2 & 47 & $M$ & $2(\mathrm{Ly}, \mathrm{Sg})$ & 6 & 50 & 8 & 1,2 & 4420 & No & MTX & DR & No & 1 & No & 30 \\
\hline 3 & 70 & $\mathrm{~F}$ & 1 (Ao) & 6 & 70 & 26 & 3,7 & 850 & MTX & No & DR & Yes(7) & 2 & No & 26 \\
\hline 4 & 49 & $M$ & $2(\mathrm{Bd}, \mathrm{Pa})$ & 6 & 60 & 39 & 1,9 & 3360 & No & No & DR & Yes(7) & 2 & No & 26 \\
\hline 5 & 52 & $M$ & $\begin{array}{c}\text { 4(Pm,Si,Or, } \\
\quad \mathrm{Pa})\end{array}$ & 15 & 90 & 7 & 21 & 1700 & No & MTX & DR & Yes(12) & 2 & No & 18 \\
\hline 6 & 52 & $M$ & $3(\mathrm{Ly}, \mathrm{Sg}, \mathrm{Lu})$ & 12 & 70 & 8 & 1,9 & 7904 & MTX & No & CR & Yes(11) & 2 & No & 18 \\
\hline 7 & 80 & $M$ & $3(\mathrm{~Pa}, \mathrm{Ly}, \mathrm{Bd})$ & 9 & 60 & 22 & 6 & 3620 & No & MTX & $\mathrm{DR}$ & Yes(9) & 2 & No & 18 \\
\hline $\begin{array}{l}\mathrm{Gr} \\
2\end{array}$ & & & & & & & & & & & & & & & \\
\hline 1 & 53 & $M$ & $\begin{array}{c}5(\mathrm{Ly}, \mathrm{Si}, \mathrm{Lg}, \\
\mathrm{Pa}, \mathrm{Sg})\end{array}$ & 12 & 80 & 7 & 0,1 & 5713 & No & $A Z A$ & $\mathrm{CR}$ & 0 & 3 & No & 18 \\
\hline 2 & 49 & $\mathrm{~F}$ & $\begin{array}{l}\text { 4(Ly,Lg,Or, } \\
\text { Ph) }\end{array}$ & 15 & 90 & 22 & 0.3 & 13800 & No & No & CR & 0 & 4 & No & 20 \\
\hline 3 & 16 & $\mathrm{~F}$ & 3(Si,Or,Ly) & 9 & 60 & 6 & 0,2 & 630 & No & No & $\mathrm{DR}$ & 0 & 7 & No & 48 \\
\hline 4 & 28 & $\mathrm{~F}$ & $\begin{array}{c}\text { 4(Hy,Pm, } \\
\text { Or,Ns) }\end{array}$ & 15 & 90 & 65 & 5,7 & 2990 & No & CTX & CR & 0 & 3 & $\begin{array}{c}\text { Yes } \\
\text { (Asthma) }\end{array}$ & 18 \\
\hline 5 & 73 & $\mathrm{~F}$ & $3(\mathrm{Or}, \mathrm{Ly}, \mathrm{Ma})$ & 12 & 70 & 17 & 1,2 & 21800 & MTX & $A Z A$ & $\mathrm{CR}$ & 0 & 5 & Yes(Rash) & 30 \\
\hline 6 & 51 & $\mathrm{~F}$ & $3(\mathrm{Lg}, \mathrm{Or}, \mathrm{Lu})$ & 12 & 70 & 16 & 6,9 & 2530 & No & No & DR & 0 & 4 & No & 18 \\
\hline 7 & 76 & $\mathrm{M}$ & $1(\mathrm{Bd})$ & 6 & 70 & 31 & 36 & 470 & No & No & DR & 0 & 3 & No & 21 \\
\hline
\end{tabular}


Methods: Data of IgG4-RD patients treated with RTX and followed-up for $>18$ months were reviewed. Patients were treated with two $1 \mathrm{~g}$ RTX doses 15 days apart(standard dose,SD) and then divided into: patients receiving $R T X$ in case of relapse(Group 1) and patients receiving maintenance RTX treatment 6 monthly(Group 2). Patients in Group 2 received a first maintenance treatment RTX SD and were then further divided into patients receiving RTX SD(Group 2a) or single $1 \mathrm{~g}$ RTX dose(Group 2b). Results: 14 IgG4-RD patients were included. Median number of organs involved was $3(1-5)$. Baseline median physician global assessment(PGA) was 70(50-90), IgG4-RD responder index(IgG4-RD RI) 12(6-12). Median eosinophil count, ESR, CRP, and serum lgG4 level were $100 \mathrm{cells} / \mu \mathrm{L}(50$ $1.800), 19 \mathrm{~mm} / \mathrm{h}(6-64), 3.7 \mathrm{mg} / \mathrm{L}(0.1-36)$ and $3.17 \mathrm{mg} / \mathrm{L}(470-21.800)$ respec tively. Indications for RTX were: relapse in $10 / 14(71 \%)$, partial response in $3 / 14(21 \%)$ and first-line treatment in $1(7 \%)$ patient. CS were stopped in 5 patients and reduced by month 3 in remaining patients $(27.14 \pm 13.06$ vs $6.43 \pm 2.45 \mathrm{mg}$ daily, $\mathrm{p}=0.012)$. 3 patients were on concomitant methotrexate(MTX) therapy at RTX induction, MTX was stopped in all patients at month 3. At month 6 PGA, IgG4-RD RI, and serum IgG4 decreased to a median value of $10(0-50), 2(0-6)$, and $822 \mathrm{mg} / \mathrm{L}(380-7.313)$, respectively $(\mathrm{p}<0.001$ for all comparisons). Median eosinophil count, CRP and ESR levels did not change significantly. 8(57.1\%), 5(35.7\%) and 1 patient $(7 \%)$ were on disease remission (DR), complete remission(CR), and partial remission(PR), respectively. Median number of RTX courses was 2(12) in Group 1, 3(3-7) in Group 2a, and 4(3-5) in Group 2b. Organ involvement, PGA, IgG4-RD RI, ESR, CRP, and serum lgG4 levels were not significantly different between the 2 Groups at baseline. FRR at 18 months in Group 1 was significantly lower than that in Group 2(29\% vs $100 \%, p=0.006)$. 5(71\%) patients in Group 1 relapsed on average 9(7$12)$ months after RTX induction. $2(14 \%)$ patients had hypersensitivity reactions during RTX induction. 6(43\%) patients, 3 in Group 1 and 3 in Group 2, experienced low-grade infections.

Conclusion: RTX is a safe and effective treatment in IgG4-RD. Both SD and single $1 \mathrm{~g}$ RTX dose seem effective in maintenance.

\section{REFERENCES:}

[1] CarruthersMN.Rituximab for IgG4-related disease:a prospective,open-label trial.Ann Rheum Dis.2015.

Disclosure of Interests: Corrado Campochiaro Consultant for: Dr Corrado Campochiaro received consultation honoraria from Pfizer., Emanuel Della Torre: None declared, Marco Lanzillotta: None declared, Enrica Bozzolo: None declared, Elena Baldissera Consultant for: Consultation honoraria from Novartis and Rottapharm, Speakers bureau: Pfeizer, Sobi, Novartis, Lorenzo Dagna Consultant for: Prof Lorenzo Dagna received consultation honoraria from Abbvie, Amgen, Biogen, Bristol-Myers Squibb, Celltrion, Novartis, Pfizer, Sanofi-Genzyme, and SOBI.

DOI: 10.1136/annrheumdis-2019-eular.5155

\section{FRI0585 EFFICACY OF CANAKINUMAB AS FIRST-LINE BIOLOGIC AGENT IN ADULT-ONSET STILL'S DISEASE}

Giulio Cavalli, Alessandro Tomelleri, Giacomo De Luca, Corrado Campochiaro, Elena Baldissera, Lorenzo Dagna. Vita-Salute San Raffale University, Unit of Immunology, Rheumatology, Allergy and Rare Diseases, Milan, Italy

Background: Adult-onset Still's disease (AOSD) is a rare auto-inflammatory condition characterized by fever, arthritis, skin rash, and multi-organ inflammation. The pathogenesis of AOSD is centrally mediated by the pro-inflammatory cytokine interleukin (IL)-1 $\beta$; anakinra, a recombinant inhibitor of the $\mathrm{IL}-1 \beta$ receptor, has thereby become the cornerstone of biologic therapy for AOSD. More recently, a new agent blocking $\mathrm{IL}-1 \beta$ has become available, that is, the monoclonal antibody canakinumab.

Objectives: So far, canakinumab has been used in the treatment of AOSD following failure of multiple lines of biologic therapy, including anakinra. Here, we describe the use of canakinumab as first-line biologic agent in 6 patients with AOSD, and report the highly promising results of this treatment approach.

Methods: Six patients with severe, DMARD-refractory AOSD received canakinumab at the approved dose of $4 \mathrm{mg} / \mathrm{kg}$ once every 4 weeks following failure of conventional treatment with corticosteroids and methotrexate. Patient characteristics and response to therapy were recorded.

Results: In all patients, treatment with canakinumab led to striking and rapid clinical responses, within days of initiation. Fever and skin rash disappeared first and did not recur, followed by progressive and sustained improvement in arthritis. Inflammatory organ involvement also responded to treatment: for example, we observed resolution of pericardial inflammation in two patients, as revealed by cardiac ultrasound; another patient had hepatosplenomegaly, which also reverted to normal upon treatment. A striking reduction in serum pro-inflammatory markers C-reactive protein erythrocyte sedimentation rate, and ferritin mirrored the efficacy on clinica manifestations. These effects amounted to a significant decrease in the modified Pouchot score for measuring disease severity (average score before canakinumab treatment: 6; after: 1.25; statistical significance of difference evaluated with Mann-Whitney: $p=0.02$ ), and allowed for tapering or discontinuation of concomitant therapy: specifically, corticosteroid treatment was completely discontinued in two patients and substantially reduced in two patients, whereas methotrexate was stopped in one patient.

Conclusion: In this study, first-line biologic therapy of AOSD with canakinumab resulted in rapid and marked efficacy, ultimately leading to full clinical remissions in all patients, and allowing for robust steroid-sparing effects. So far, canakinumab in AOSD has mostly been used as a last line of treatment following failure of multiple other agents, including anakinra. Early treatment, as described in this study, is nevertheless advisable and may reduce chances of chronic disease and permanent damage.

\section{REFERENCES:}

[1] Cavalli G, Dinarello CA: Treating rheumatological diseases and co-morbidities with interleukin-1 blocking therapies. Rheumatology (Oxford) 2015, 54 (12):2134-2144.

[2] Cavalli G, Franchini S, Aiello P, Guglielmi B, Berti A, Campochiaro C, Sab badini MG, Baldissera E, Dagna L: Efficacy and safety of biological agents in adult-onset Still's disease. Scand J Rheumatol 2015, 44(4):309-314.

Disclosure of Interests: Giulio Cavalli: None declared, Alessandro Tomelleri: None declared, Giacomo De Luca Speakers bureau: Pfeizer, Sobi, Corrado Campochiaro Consultant for: Dr Corrado Campochiaro received consultation honoraria from Pfizer., Elena Baldissera Consultant for: Consultation honoraria from Novartis and Rottapharm, Speakers bureau: Pfeizer, Sobi, Novartis, Lorenzo Dagna: None declared DOI: 10.1136/annrheumdis-2019-eular.451

\section{FRI0586 THE EFFECT OF TOCILIZUMAB IN THE PREVENTION OF FAMILIAL MEDITERRANEAN FEVER ATTACKS}

Seda Colak, Emre Tekgoz, Muhammet Çınar, Sedat Yilmaz. University of Health Sciences, Gulhane Faculty of Medicine, Department of Internal Medicine, Division of Rheumatology, Ankara, Turkey

Background: Familial Mediterranean Fever (FMF) is the most frequent hereditary autoinflammatory disease in the worldwide. Colchicine is the mainstay of the treatment that is used for both preventing the attacks and developing amyloidosis. In case of colchicine resistance, which constitutes almost $5 \%$ of all patients, there are some alternatives such as anti-TNF agents, IL- 6 and IL- 1 antagonists. These agents have also been used in patients with established amyloidosis secondary to FMF. Tocilizumab (TCZ), an IL-6 receptor antagonist, although is effective in the treat ment of amyloidosis, little known about its effectiveness in the preventing of febrile attacks.

Objectives: In this study, we aimed to find out whether TCZ therapy decrease the frequency of recurrent attacks of FMF or not.

Methods: This retrospective cross-sectional study designed in a tertiary rheumatology clinic between the years 2009 and 2019. A total of 15 patients were given intravenous TCZ at a dose of $8 \mathrm{mg} / \mathrm{kg} / \mathrm{month}$, to improve amyloidosis associated with FMF. Data of demographic and clinical characteristics of patients were obtained retrospectively from patient files.

Results: Three female and 12 male patients received TCZ for amyloidosis treatment. The mean age of patients was $42.07 \pm 14.37$ years and disease duration was $25.73 \pm 10.86$ years. All of the patients had biopsy results providing amyloidosis. According to international severity scoring system for FMF, all of the patients had severe disease. Demographic and clinica data were shown in Table 1. The frequency of attacks was evaluated during TCZ treatment, and it was reported that 1 patient had no response, 6 patients had decreased attack frequency and 8 patients had no attacks. Serious adverse events were seen in none of the patients. 